\title{
The effects of residential environment on the condition and fitness of soccer players in the summer
}

\author{
Jae-Hoon Jang', Chang-Hwa Joo ${ }^{2,3, *}$ \\ 'Department of Football Science, Honam University, Gwangju, Korea \\ 2Department of Sport Science, Kangwon National University, Chuncheon, Korea \\ ${ }^{3}$ Interdisciplinary Program in Biohealth-machinery Convergence Engineering, Kangwon National University, Chuncheon, Korea
}

Exercise performance is reduced in hot environments due to physiological responses caused by increased body temperature. A proper residential environment is important for improving the performance and maintaining physical condition of soccer players in the summer. The purpose of this study was to determine the effect of indoor temperature of the resting space during the summer on the fitness and condition of soccer players. A total of $12 \mathrm{~K}-3$ League semiprofessional players without serious injuries in the last 3 months voluntarily participated in the study. Participants performed speed ( $10 \mathrm{~m}, 20 \mathrm{~m}$, and $30 \mathrm{~m}$ ), soccer-specific coordination skill (dribbling), agility, repeated sprints, Yo-Yo intermittent level 2, vertical jump, and questionnaire (fatigue, sleep quality, muscle soreness, stress, and mood) after staying indoor temperature at $20^{\circ} \mathrm{C}, 26^{\circ} \mathrm{C}$, and $30^{\circ} \mathrm{C}$ for one night, respectively. There was no difference among groups in physical fitness (speed, agility, jump, coordina- tion, $Y_{0}-Y_{0}$ intermittent level 2, and repeated sprints). The differences in fatigue and sleep quality were not statistically significant among groups, but they tended to be different. Muscle soreness was similar among all groups. Significant differences were observed between the ${ }^{\circ} 0^{\circ} \mathrm{C}$ and $30^{\circ} \mathrm{C}$ groups in stress and mood levels. The present study concluded that, while the physical fitness did not differ among groups, the $30^{\circ} \mathrm{C}$ residential environment was shown to have a negative psychological effect. Considering that many diseases associated with hot weather occur in low residential temperatures, a room temperature of $26^{\circ} \mathrm{C}$ is recommended for elite soccer players in hot summer weather.

Keywords: Residential environment, Sleeping temperature, Psychology, Physical fitness

\section{INTRODUCTION}

Several factors need to be considered to win a soccer match. Continuous error-free accuracy of playing is almost impossible throughout a 90-min soccer match. To maintain clear decision during the match and reduce skill-related errors, the ability to psychologically and physically resist fatigue is essential for the players (Coutinho et al., 2017). The average total distance covered by professional soccer players during a match is approximately $11.9 \mathrm{~km}$, with highintensity running, and sprinting comprising $8 \%$ of the movements (Joo and Jee, 2019). Therefore, high-intensity physical training to improve fitness is an essential element for soccer players preparing for a match. Due to several advances in sports science, soccer players can now complete fitness training systematically and efficient- ly while reducing the risk of injury through developed training methods and equipment.

Soccer players often have to play in hot environments for certain periods due to the nature of the tournament venue and the duration of the professional soccer league. Players undergo added physical stress when playing in a hot environment. It is well known that athletic performance is reduced in hot environments due to physiological responses caused by increased body temperature (Mohr and Krustrup, 2013; Mohr et al., 2010). Several physiological factors reduce athletes' performance in hot environments; among these, restriction of nerve signals in the central and peripheral nervous system due to the accumulated fatigue substances and muscle fatigue caused by loss of body water and electrolytes are the main causes (Nybo, 2008; Roelands and Meeusen, 2010). In extreme cases,
${ }^{*}$ Corresponding author: Chang-Hwa Joo (iD https://orcid.org/0000-0002-7429-3104 Department of Sport Science, Kangwon National University, 1 Kangwondaehak-gil, Chuncheon 24341, Korea

E-mail: phd.football@gmail.com

Received: October 15, 2020 / Accepted: November 21, 2020
This is an Open Access article distributed under the terms of the Creative Commons Attribution Non-Commercial License (https://creativecommons.org/licenses/by-nc/4.0/) which permits unrestricted non-commercial use, distribution, and reproduction in any medium, provided the original work is properly cited. 
athletes are unable to exercise due to heat stroke. Therefore, to quickly recover and maintain the condition of the players, it is necessary to bring down the raised body temperature in a short period after a match. To this end, recovery methods such as cold-water immersion have been developed and are widely used by athletes.

A proper resting environment, along with various recovery and nutritional methods, is important for improving the performance and maintaining physical condition of soccer players. In addition, the amount and quality of sleep, which can affect athletes' performance, depends on the sleep environment. Environmental factors such as the room temperature and humidity in hot summer nights are strongly associated with the amount and quality of sleep (Guozhong et al., 2019). High room temperatures can interfere with athletes' sleep, and excessively low room temperatures through the use of air conditioners can lead to disturbed sleep as well as diseases such as "air-conditioningitis" (Gilbert et al., 2004). A room temperature of $26^{\circ} \mathrm{C}$ is recommended by the Korean government in summer to prevent diseases related to low room temperature as well as to improve energy saving. However, soccer players normally stay and rest at lower room temperatures in their homes and clubhouses before training and matches.

Despite the fact that the rest environment during summer can have a significant impact on performance and controlling physical condition of soccer players, little research has been conducted on the effects of the room temperature on fitness and condition. The purpose of this study was to determine the effect of indoor temperature of the resting space during the summer on the fitness and condition of soccer players.

\section{MATERIALS AND METHODS}

\section{Subjects}

A total of 12 K-3 League semiprofessional players without serious injuries in the last 3 months voluntarily participated in the study. Goalkeepers were excluded from the study because of their low physical requirements compared to those needed for other positions. Initially, 16 players participated; four dropped out for personal and injury-related reasons (mean age, $23 \pm 2$ years; mean height, $175 \pm 6 \mathrm{~cm}$; mean body mass, $71 \pm 5 \mathrm{~kg}$ ). All subjects had no history of neurological disease or musculoskeletal abnormality; none of them was undergoing any pharmacological treatment during the course of the study.

\section{Procedures}

To determine whether indoor temperature of the resting space affects the fitness and condition of soccer players during the summer. All procedures performed in the study were approved by the Kangwon National University Ethics Committee (KWNUIRB2019-05-002-002). During the enrolment process, all players gave written informed consent to participate after details and procedures of the study had been fully explained.

The study was conducted during the summer break of the K-3 League (July-August). A specific order of conditions was set for the players who completed the study participation agreement. Three groups were created on the basis of temperature $\left(30^{\circ} \mathrm{C}\right.$, normal room temperature; $26^{\circ} \mathrm{C}$, recommended room temperature; and $20^{\circ} \mathrm{C}$, preferred room temperature); each athlete selected a random group from several sealed paper envelopes. In the group setting of condition 2, the group was assigned by selecting the envelope in the same manner between the two groups except for the group conducted in condition 1. In condition 3, the other group that was not included in condition 1 and 2 was implemented (Fig. 1).

The experimental design is shown in Fig. 2. For the experiment, the players rested and slept at the designated room temperature $\left(30^{\circ} \mathrm{C} \pm 0.7^{\circ} \mathrm{C}, 26^{\circ} \mathrm{C} \pm 0.6^{\circ} \mathrm{C}\right.$, or $\left.20^{\circ} \mathrm{C} \pm 0.6^{\circ} \mathrm{C}\right)$ from $6: 00$ p.m. to 10:00 a.m. Subjects' height was measured whilst standing in the Frankfurt plane using a stadiometer (Seca, Birminghm, UK) and body mass was recorded, whilst nude, using precision calibrated weighing scales (Seca) before the experiment. A heart rate monitor (Polar S610i, Kempele, Finland) was worn to monitor the changes in heart rate during sleep. The players answered a questionnaire to assess sleep quality and conditions at 7:00 a.m. after waking up. A fitness test (jump, speed), coordination, agility, repeated sprints, Yo-Yo intermittent recovery level 2 (Yo-Yo IR2) were conducted with sufficient warm-up at 10:00 a.m. $\left(32^{\circ} \mathrm{C} \pm\right.$ $\left.1.5^{\circ} \mathrm{C}, 50 \% \pm 10 \%\right)$. The experiment was repeated with a time interval of at least one week between experiments. The players conducted normal team training during the 1-week period after

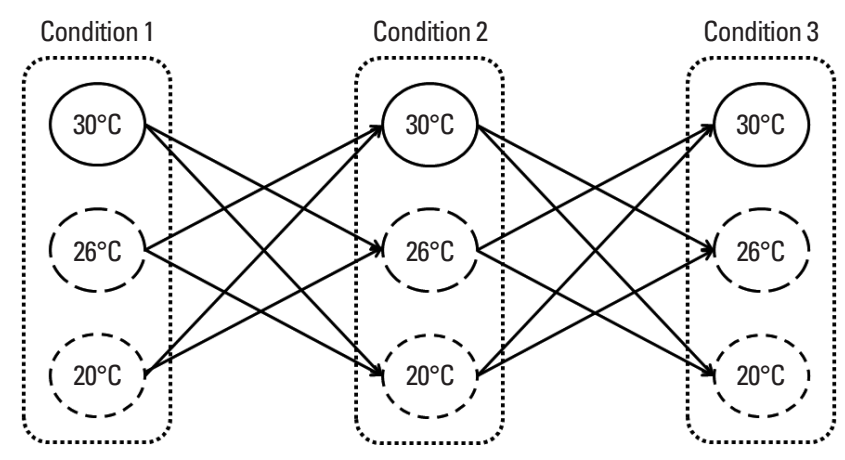

Fig. 1. Schematic illustration of grouping. 


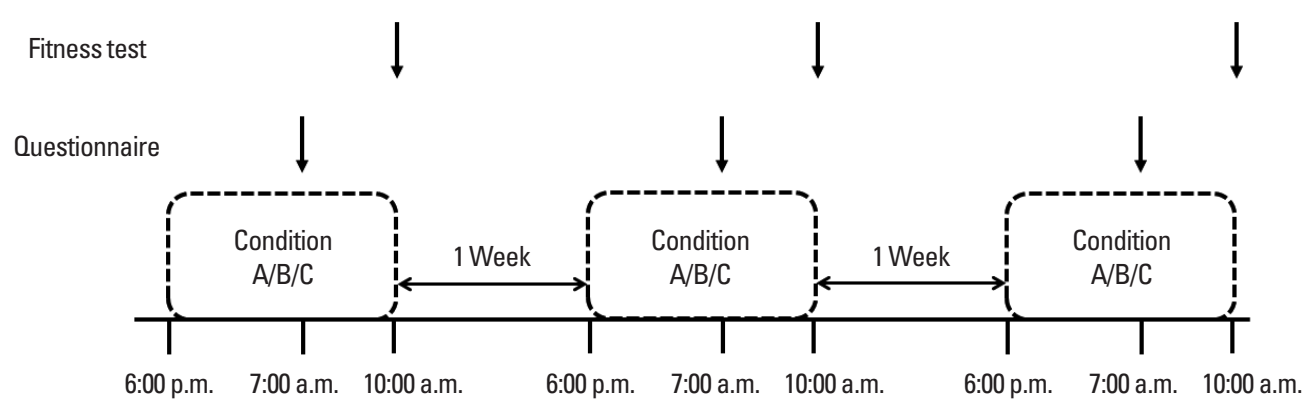

Fig. 2. Schematic illustration of the experimental design.

the experiment, and the training sessions were organised in the same way as those after the previous experiment to ensure consistent training volume and intensity.

\section{0-m sprint test}

The sprint tests which consisted of 2 maximal sprints of $30 \mathrm{~m}$ with 2-min rest between each sprint were conducted. The sprint times at 10, 20, and $30 \mathrm{~m}$ were recorded using the photocell gates (Microgate, Bolzano, Italy). The participants started to run $50 \mathrm{~cm}$ before the photocell gate recordings. The fastest times at the distances were recorded for data analysis.

\section{Arrowhead agility test}

The arrowhead agility tests consisted of 4 sprints (2 right, 2 left), with 2-min rest between each sprint (Noon et al., 2015). Each subject started $50 \mathrm{~cm}$ behind the start line and sprinted $10 \mathrm{~m}$ forward to a cone. From the cone, the subjects turned at a right angle to a cone being apart from $5 \mathrm{~m}$ before turning to a cone $15 \mathrm{~m}$ straight from the start line. They turned again from the cone to accelerate in a straight line for $15 \mathrm{~m}$ over the initial start line to complete the run. The fastest times were recorded for data analysis. Timing gates were used to accurately assess the time to completion.

\section{Vertical jump}

The players completed vertical jump twice on a pad with sort of compatible height measurer attached (Nike SPARQ, Nike Inc., Beaverton, OR, USA) (Burris et al., 2020). Each player strated standing with both feeth on the pad and perfomed jump with full arm swing to initiate the jump. The highest score was recorded for data analysis.

\section{Coordination}

The players completed soccer-specific coordination skill which consisted of the 44-m slalom dribble twice with 5-min rest between each test (Joo, 2016). Each player started $50 \mathrm{~cm}$ behind the start line and dribbled a ball around 14 cones. If the subject touches the cones, 2 sec were added to the recording time. The fastest times were recorded for data analysis. the photocell gates (Microgate) were used to accurately assess the time to completion.

\section{Yo-Yo intermittent recovery test (level 2)}

The Yo-Yo IR2 test was performed on an artificial turf. The YoYo IR 2 test consists of $2 \times 20$-m shuttle runs at increasing speeds, controlled by audio signals from a compact disk. Between each bout of running, the subjects completed $10 \mathrm{sec}$ of active recovery, consisting of $2 \times 5-\mathrm{m}$ jogging (Bangsbo et al., 2008). The test was terminated when the subjects failed twice to reach the start line on time and the distance $(\mathrm{m})$ covered at the end point was recorded (Thomassen et al., 2010).

\section{Repeated sprint test}

The repeated sprint test consisted of seven maximal 34.2-m sprints, interspersed by $25 \mathrm{sec}$ of active recovery (40-m jogging distance) (Abrantes et al., 2004). Recovery was timed so that the subjects returned to the start line whihin 25 seconds. Additionally, verbal feedback was given at 5, 10, 15, and $20 \mathrm{sec}$ of the recovery. Performance was measured as the total sprint time in seconds and fatigue index. A repeated sprint fatigue index was calculated as fatigue index $=$ (slowest sprint time-fastest sprint time) $/$ fastest sprint time $\times 100 \%$.

\section{Questionnaire}

The questionnaire to check the condition (well-being) of the players was based on a questionnaire used in a previous study (McLean et al., 2010). This scale consists of 5 subjective ratings that evaluate fatigue, sleep quality, muscle soreness, stress, and mood. Each question was rated on a 5-point Likert scale from 1 
Table 1. Player condition screening questionnaire

\begin{tabular}{|c|c|c|c|c|c|}
\hline \multirow{2}{*}{ Variable } & \multicolumn{5}{|c|}{ Score } \\
\hline & 1 & 2 & 3 & 4 & 5 \\
\hline Fatigue & Always tired & More tired than normal & Normal & Fresh & Very fresh \\
\hline Sleep quality & Insomnia & Restless sleep & Difficulty falling asleep & Good & Very restful \\
\hline General muscle soreness & Very sore & Increase in soreness/tightness & Normal & Feeling good & Feeling great \\
\hline Stress level & Highly stressed & Feeling stressed & Normal & Relaxed & Very relaxed \\
\hline Mood & Highly annoyed/irritable down & Aggravated/short tempered & $\begin{array}{l}\text { Less interested in others and/ } \\
\text { or activities than usual }\end{array}$ & A generally good mood & Very positive mood \\
\hline
\end{tabular}

Table 2. Summary of physical fitness in $20^{\circ} \mathrm{C}, 26^{\circ} \mathrm{C}$, and $30^{\circ} \mathrm{C}$

\begin{tabular}{lcccc}
\hline \multirow{2}{*}{ Variable } & \multicolumn{4}{c}{ Trial } \\
\cline { 2 - 4 } & $20^{\circ} \mathrm{C}$ & $26^{\circ} \mathrm{C}$ & $30^{\circ} \mathrm{C}$ & F-value \\
\hline Speed (sec) & & & & \\
$10 \mathrm{~m}$ & $1.75 \pm 0.12$ & $1.70 \pm 0.09$ & $1.73 \pm 0.11$ & 0.779 \\
$20 \mathrm{~m}$ & $3.07 \pm 0.19$ & $2.99 \pm 0.14$ & $3.02 \pm 0.19$ & 0.628 \\
$30 \mathrm{~m}$ & $4.36 \pm 0.32$ & $4.21 \pm 0.20$ & $4.26 \pm 0.26$ & 0.991 \\
Agility (sec) & & & & \\
$\quad$ Right & $8.55 \pm 0.32$ & $8.53 \pm 0.33$ & $8.51 \pm 0.25$ & 0.041 \\
Left & $8.63 \pm 0.41$ & $8.58 \pm 0.33$ & $8.57 \pm 0.27$ & 0.097 \\
Jump (cm) & $57.17 \pm 4.75$ & $56.25 \pm 6.09$ & $56.92 \pm 5.23$ & 0.093 \\
Coordination (sec) & $14.10 \pm 0.71$ & $13.80 \pm 0.89$ & $14.43 \pm 1.46$ & 1.063 \\
Yo-Yo intermittent & $831.67 \pm 179.56$ & $873.33 \pm 141.51$ & $836.67 \pm 202.86$ & 0.199 \\
$\quad$ level 2 (m) & & & & \\
Repeated sprint test & & & & \\
$\quad$ Total time (sec) & $48.84 \pm 2.37$ & $48.34 \pm 1.84$ & $48.03 \pm 1.23$ & 0.576 \\
Fatigue index (\%) & $5.53 \pm 3.26$ & $5.46 \pm 1.87$ & $6.71 \pm 4.01$ & 0.585 \\
\hline
\end{tabular}

Values are presented as mean \pm standard deviation $(n=12)$.

(i.e., indicate "extreme") to 5 (i.e., indicate "not at all") (Table 1).

\section{Statistical analysis}

Statistical analyses were carried out using IBM SPSS Statistics ver. 23.0 (IBM Co., Armonk, NY, USA). Data are presented as mean values \pm standard deviation. All variables were approved by Shapiro-Wilk normality test. One-way analysis of variance was performed to analyse the differences in physical fitness and condition among the groups and Bonferroni test was used as the post hoc test. The alpha level for evaluation of statistical significance was set at $P<0.05$.

\section{RESULTS}

The results of the players' fitness tests are shown in Table 2. There was no difference among groups in physical fitness (speed, agility, jump, coordination, Yo-Yo IL2, and repeated sprints) $(P>$ $0.05)$. Psychological variables (fatigue, sleep quality, muscle sore-
Table 3. Summary of psychological variables in $20^{\circ} \mathrm{C}, 26^{\circ} \mathrm{C}$, and $30^{\circ} \mathrm{C}$

\begin{tabular}{|c|c|c|c|c|c|}
\hline \multirow{2}{*}{ Variable } & \multicolumn{3}{|c|}{ Trial } & \multirow{2}{*}{ F-value } & \multirow{2}{*}{$\begin{array}{l}\text { Post } \\
\text { hoc }\end{array}$} \\
\hline & $20^{\circ} \mathrm{C}(\mathrm{a})$ & $26^{\circ} \mathrm{C}$ & $30^{\circ} \mathrm{C}(\mathrm{c})$ & & \\
\hline Fatigue (a.u.) & $3.08 \pm 0.90$ & $2.33 \pm 0.89$ & $2.25 \pm 0.87$ & 3.229 & - \\
\hline Sleep quality (a.u.) & $3.67 \pm 0.89$ & $4.00 \pm 0.60$ & $3.17 \pm 1.03$ & 2.863 & - \\
\hline Muscle soreness (a.u.) & $2.83 \pm 0.58$ & $2.83 \pm 0.84$ & $2.58 \pm 0.52$ & 0.579 & - \\
\hline Stress (a.u.) & $3.58 \pm 0.10$ & $3.00 \pm 0.60$ & $2.67 \pm 0.49$ & $4.848^{*}$ & $a>c$ \\
\hline Mood (a.u.) & $3.58 \pm 0.52$ & $3.33 \pm .078$ & $2.75 \pm 0.72$ & $5.235^{*}$ & $a>c$ \\
\hline
\end{tabular}

Values are presented as mean \pm standard deviation $(n=12)$.

a.u., arbitrary unit.

${ }^{*}$ Significant difference among conditions $(P<0.05)$.

ness, stress, and mood) are shown in Table 3. The differences in fatigue and sleep quality were not statistically significant among groups, but they tended to be different $(P=0.052, P=0.07)$. The $30^{\circ} \mathrm{C}$ group experienced the most fatigue, followed by the $26^{\circ} \mathrm{C}$ and $20^{\circ} \mathrm{C}$ groups. Sleep quality was highest in the $26^{\circ} \mathrm{C}$ group and lowest in the $30^{\circ} \mathrm{C}$ group. Muscle soreness was similar among all groups $(P=0.57)$. Significant differences were observed between the $20^{\circ} \mathrm{C}$ and $30^{\circ} \mathrm{C}$ groups in stress and mood levels $(P=0.01$, $P=0.01)$. The stress level was higher in the $30^{\circ} \mathrm{C}$ group than in the $20^{\circ} \mathrm{C}$ group $(P=0.01)$, whereas the mood level was lowest in the $30^{\circ} \mathrm{C}$ group $(P=0.01)$.

\section{DISCUSSION}

The major finding of the present study was that physical fitness was not affected by the resting environment, but differences were found in psychological variables. In particular, fatigue, sleep quality, stress, and mood levels were negatively affected at $30^{\circ} \mathrm{C}$ compared to the resting conditions of $26^{\circ} \mathrm{C}$ and $20^{\circ} \mathrm{C}$.

To the best of our knowledge, there is no research on the relationship between resting indoor environment and soccer player performance in summers. Therefore, we hypothesised that players' physical fitness level was strongly affected by the living and resting environment (i.e., temperature) in the summer. However, we 
found that the players' housing environment was not significantly related to their fitness performance. Several previous studies have shown that exercise performance at high temperatures is lower than performance at normal temperatures (Guy et al., 2015; Nassis et al., 2015; Sunderland and Nevill, 2005). For example, the number of sprint performance at high environment stress was $10 \%$ lower than moderate or low environmental stress (Nassis et al., 2015). Moreover, total game distance and high-intensity running ( $>14 \mathrm{~km} / \mathrm{hr}$ ), which requires continuous high-intensity exercise for a long time compared to explosive exercise in a short time such as sprint, was more affected by the exercise environment during soccer match (Mohr et al., 2012). Taken together, it can be concluded that players' exercise performance is more affected by the environment in which they actually exercise than their residential environment.

The fitness level of the players participating in this experiment was lower than that of the professional soccer players that were included in a previous study (Bradley et al., 2013). The Yo-Yo IL 2 results were lower than those of European professional soccer players (Christensen et al., 2011). These differences in fitness levels can be attributed to differences in league levels, measurement timing, and conditions. In general, players in high-level leagues have higher fitness levels than players in lower leagues (Sæterbakken et al., 2019). In addition, this study was conducted during the summer break period after the first half of the season; therefore, it can be assumed that the result of low level of fitness is due to the accumulated fatigue of players. In terms of the measurement environment, it is likely that the lower level of fitness was partly due to the hot test environment.

Unlike the physical fitness results, the psychological variables of players according to residential environment were found to show statistically significant differences in stress and mood and a tendency to differences in fatigue and sleep quality. The difference in the results of the physical and psychological factors is due to the sensitivity of players' response. Players might be more sensitive to psychological responses than physical responses. For example, physical fitness of elite players such as total time of repeated sprints, fatigue index, and jump height was not changed in afternoon training compared to morning training, but difference in psychological variables such as rate of perceived exertion, vigour scores, and stress was observed (Chtourou et al., 2018). These results indicate that differences in residential environment in the summer affect sensitive psychological factors but are considered to be sufficient longterm stimuli to change physical fitness factors.

Higher than normal fatigue was observed in all groups due to the summer training. Players experienced lower fatigue when they slept and rested at a temperature of $20^{\circ} \mathrm{C}$ compared to a temperature of $30^{\circ} \mathrm{C}$. There may be a variety of reasons for the different levels of fatigue among residential environments, but sleep may be closely related. Sufficient amount of sleep and quality of the sleep are critical to maximizing the training response and maintaining players' condition (Samuels et al., 2016). In the current study, sleep time $(7.5 \pm 0.4 \mathrm{hr})$ and mean heart rate $(56 \pm 8$ beats) during sleep were similar among all groups. However, sleep quality was the highest in the $26^{\circ} \mathrm{C}$ group, followed by the $20^{\circ} \mathrm{C}$ and $30^{\circ} \mathrm{C}$ groups. These results were in line with those of a previous study that indicated that controlling the stable environmental temperature is an important factor, because excessively high or low environmental temperatures can cause problems with sleep quantity and quality (Gilbert et al., 2004). Lower quality of sleep in hot or cold environments is caused by disturbed rapid eye movement sleep and slow-wave sleep (Haskell et al., 1981).

Muscle soreness was not different among the groups in the current study (2.53-2.83). This result is due to a week of training before the test did not cause injury to the players. While muscle injuries usually occur with repeated unfamiliar eccentric movements, and muscle soreness lasts over a period of 5 to 7 days (Cleak and Eston, 1992), the players performed familiar exercise for a week without muscle injury in the current study. Indeed, soccer players have a low risk of muscle injury for physically adapted movements due to the repeated bout effect that occurs through long training sessions (McHugh, 2003). In addition, various methods are applied to recover from injury or fatigue after training or competition; for example, cold-water immersion is widely used for soccer players (Leeder et al., 2012). In current study, the same exercise volume and intensity were conducted for a week before the fitness test, and no special recovery method was applied except the dynamic recovery after the training. Therefore, it is thought that players did not develop muscle injuries and there was no difference in muscle soreness according to the residential environments.

Interestingly, stress and mood scores differed between groups, and players felt the most stress and negative feelings at the $30^{\circ} \mathrm{C}$ condition. These results were consistent with the results of a previous study, where despite changes in stress and mood scores, no differences in fitness levels were found (Chtourou et al., 2018). As mentioned earlier, differences in stress and mood scores according to residential conditions may be closely related to sleep quality. We studied the effects of acute (16 hours, 6:00 p.m.-10:00 p.m.) response to different residential conditions, rather than chronic response (days or weeks). Previous study reported that 21 days of 
living in a normobaric hypoxic environment improves exercise performance of competitive runners at sea level (Park et al., 2019). Based on previous finding, long-term residential conditions can lead to different physical and psychological responses for soccer players. Therefore, further research is needed to investigate the effects of long-term residential environment on the fitness and condition of players.

In the current study, we analysed the differences in physical fitness and psychological variables according to summer residential environments $\left(20^{\circ} \mathrm{C}, 26^{\circ} \mathrm{C}\right.$, and $\left.30^{\circ} \mathrm{C}\right)$. Similar fitness factors were observed among the three conditions, but there were differences in psychological variables. The $30^{\circ} \mathrm{C}$ residential environment was shown to have a negative psychological effect, while no statistically significant differences were found between the $20^{\circ} \mathrm{C}$ and $26^{\circ} \mathrm{C}$ conditions. Considering that many diseases associated with hot weather such as "air-conditioningitis" occur in low residential temperatures, a room temperature of $26^{\circ} \mathrm{C}$ is recommended for elite soccer players in hot summer weather.

\section{CONFLICT OF INTEREST}

No potential conflict of interest relevant to this article was reported.

\section{REFERENCES}

Abrantes C, Macas V, Sampaio J. Variation in football players' sprint test performance across different ages and levels of competition. J Sports Sci Med 2004;3:44-49.

Bangsbo J, Iaia FM, Krustrup P. The Yo-Yo intermittent recovery test: a useful tool for evaluation of physical performance in intermittent sports. Sports Med 2008;38:37-51.

Bradley PS, Carling C, Gomez DA, Hood P, Barnes C, Ade J, Boddy M, Krustrup P, Mohr M. Match performance and physical capacity of players in the top three competitive standards of English professional soccer. Hum Mov Sci 2013;32:808-821.

Burris K, Liu S, Appelbaum L. Visual-motor expertise in athletes: insights from semiparametric modelling of 2317 athletes tested on the Nike SPARQ Sensory Station. J Sports Sci 2020;38:320-329.

Christensen PM, Krustrup P, Gunnarsson TP, Kiilerich K, Nybo L, Bangsbo $\mathrm{J}$. $\mathrm{VO}_{2}$ kinetics and performance in soccer players after intense training and inactivity. Med Sci Sports Exerc 2011;43:1716-1724.

Chtourou H, Engel FA, Fakhfakh H, Fakhfakh H, Hammouda O, Ammar A, Trabelsi K, Souissi N, Sperlich B. Diurnal variation of short-term repetitive maximal performance and psychological variables in elite judo athletes. Front Physiol 2018;26:1499.

Cleak MJ, Eston RG. Delayed onset muscle soreness: mechanisms and management. J Sports Sci 1992;10:325-341.

Coutinho D, Gonçalves B, Travassos B, Wong DP, Coutts AJ, Sampaio JE. Mental fatigue and spatial references impair soccer players' physical and tactical performances. Front Psychol 2017;21:1645.

Gilbert SS, van den Heuvel CJ, Ferguson SA, Dawson D. Thermoregulation as a sleep signalling system. Sleep Med Rev 2004;8:81-93.

Guozhong Z, Ke L, Yajing W. The effects of high-temperature weather on human sleep quality and appetite. Int J Environ Res Public Health 2019;16:270.

Guy JH, Deakin GB, Edwards AM, Miller CM, Pyne DB. Adaptation to hot environmental conditions: an exploration of the performance basis, procedures and future directions to optimise opportunities for elite athletes. Sports Med 2015;45:303-311.

Haskell EH, Palca JW, Walker JM, Berger RJ, Heller HC. The effects of high and low ambient temperatures on human sleep stages. Electroencephalogr Clin Neurophysiol 1981;51:494-501.

Joo $\mathrm{CH}$. The effects of short-term detraining on exercise performance in soccer players. J Exerc Rehabil 2016;12:54-59.

Joo $\mathrm{CH}$, Jee $\mathrm{H}$. Activity profiles of top-class players and referees and accuracy in foul decision-making during Korean national league soccer games. J Strength Cond Res 2019;33:2530-2540.

Leeder J, Gissane C, van Someren K, Gregson W, Howatson G. Cold water immersion and recovery from strenuous exercise: a meta-analysis. Br J Sports Med 2012;46:233-240.

McHugh MP. Recent advances in the understanding of the repeated bout effect: the protective effect against muscle damage from a single bout of eccentric exercise. Scand J Med Sci Sports 2003;13:88-97.

McLean BD, Coutts AJ, Kelly V, McGuigan MR, Cormack SJ. Neuromuscular, endocrine, and perceptual fatigue responses during different length between-match microcycles in professional rugby league players. Int J Sports Physiol Perform 2010;5:367-383.

Mohr M, Krustrup P. Heat stress impairs repeated jump ability after competitive elite soccer games. J Strength Cond Res 2013;27:683-689.

Mohr M, Nybo L, Grantham J, Racinais S. Physiological responses and physical performance during football in the heat. PLoS One 2012;7: e39202.

Mohr M, Mujika I, Santisteban J, Randers MB, Bischoff R, Solano R, Hewitt A, Zubillaga A, Peltola E, Krustrup P. Examination of fatigue development in elite soccer in a hot environment: a multi-experimental approach. Scand J Med Sci Sports 2010;20(Suppl 3):125-132.

Nassis GP, Brito J, Dvorak J, Chalabi H, Racinais S. The association of environmental heat stress with performance: analysis of the 2014 FIFA World Cup Brazil. Br J Sports Med 2015;49:609-613. 
Noon MR, James RS, Clarke ND, Akubat I, Thake CD. Perceptions of wellbeing and physical performance in English elite youth footballers across a season. J Sports Sci 2015;33:2106-2115.

Nybo L. Hyperthermia and fatigue. J Appl Physiol 2008;104:871-878.

Park HY, Park W, Lim K. Living high-training low for 21 days enhances exercise economy, hemodynamic function, and exercise performance of competitive runners. J Sports Sci Med 2019;18:427-437.

Roelands B, Meeusen R. Alterations in central fatigue by pharmacological manipulations of neurotransmitters in normal and high ambient temperature. Sports Med 2010;40:229-246.

Samuels C, James L, Lawson D, Meeuwisse W. The athlete sleep screening questionnaire: a new tool for assessing and managing sleep in elite athletes. Br J Sports Med 2016;50:418-422.

Sæterbakken A, Haug V, Fransson D, Grendstad HN, Gundersen HS, Moe VF, Ylvisaker E, Shaw M, Riiser A, Andersen V. Match running performance on three different competitive standards in Norwegian soccer. Sports Med Int Open 2019;16:E82-88.

Sunderland C, Nevill ME. High-intensity intermittent running and field hockey skill performance in the heat. J Sports Sci 2005;23:531-540.

Thomassen M, Christensen PM, Gunnarsson TP, Nybo L, Bangsbo J. Effect of 2-wk intensified training and inactivity on muscle $\mathrm{Na}^{+}-\mathrm{K}^{+}$pump expression, phospholemman (FXYD1) phosphorylation, and performance in soccer players. J Appl Physiol 2010;108:898-905. 